\title{
Development of a sensitive and stable GC-MS/MS method for simultaneous determination of four N-nitrosamine genotoxic impurities in sartan substances
}

Jie Liu', Bin Xie ${ }^{1}$, Binliang Mai ${ }^{2}$, Qiang Cai ${ }^{1}$, Rujian $\mathrm{He}^{2}$, Dong Guo ${ }^{2,3}$, Zhifeng Zhang ${ }^{2}$, Jun Fan ${ }^{2 *}$ (1) and Weiguang Zhang ${ }^{2^{*}}$

\begin{abstract}
Recently, N-nitrosamines have been unexpectedly found in generic sartan products. Herein, we developed a sensitive and stable GC-MS/MS method with multiple reactions monitoring mode for the simultaneous determination of four $\mathrm{N}$-nitrosamines in sartan substances, namely, $\mathrm{N}$-nitrosodimethylamine, $\mathrm{N}$-nitrosodiethylamine, $\mathrm{N}$-nitrosodibutylamine, and N-nitrosodiisopropylamine. The conditions of gas chromatography and mass spectrometry were optimized. The method was validated according to the International Council for Harmonization guidelines in terms of sensitivity, linearity, accuracy, precision, specificity, and stability. The limits of detection of Nnitrosamines in sartan substances ranged from 0.002 to $0.150 \mathrm{ppm}$, and the corresponding limits of quantification were in the range of 0.008-0.500 ppm, which met the sensitivity requirements for the limits set by the Food and Drug Administration of the United States. The internal standard curve of four N-nitrosamines showed good linearity of regression coefficients over 0.99 . The recoveries of $\mathrm{N}$-nitrosamines in selected sartan drugs ranged from 87.68 to $123.76 \%$. The intraday and interday relative standard deviation values were less than $9.15 \%$. Therefore, this proposed method exhibited good sensitivity and precision, high accuracy, and fast analysis speed, which provide a reliable method for quality control of $\mathrm{N}$-nitrosamines in sartan products.
\end{abstract}

Keywords: Sartan substances, N-nitrosamine genotoxic impurity, GC-MS/MS, Multiple reactions monitoring, Quantitative determination

\section{Introduction}

In the manufacturing processes of active pharmaceutical ingredients (APIs), impurities are generated from a variety of sources, such as starting materials, intermediates, reagents, solvents, catalysts, and by-products. As a kind of special impurities, genotoxic impurities (GTIs) could induce genetic mutations, cause chromosomal breakage and rearrangements, and increase the risk of cancer even under a low concentration condition (Szekely et al. 2015;

\footnotetext{
*Correspondence: fanj@scnu.edu.cn; wgzhang@scnu.edu.cn

${ }^{2}$ School of Chemistry, South China Normal University, Guangzhou 510006, China

Full list of author information is available at the end of the article
}

Benigni and Bossa 2011). Therefore, the European Medicines Agency and Food and Drug Administration (FDA) of the USA have established a threshold of toxicological concern for GTIs, namely, $1.5 \mu \mathrm{g} \cdot$ day $^{-1}$ for long-term treatments and higher limits for shorter durations in the clinic (Raman et al. 2011). In a view of the low concentration level, the development of a sensitive, highefficient, and robust analytical methodology for detecting potential GTIs in APIs has been a great challenge for the pharmaceutical industry in recent years (Teasdale and Elder 2014).

Sartan substances are one of the most frequently prescribed antihypertensive drugs and have been widely 
applied in the treatment of cardiovascular diseases all over the world (Muszalska et al. 2014). In the production process of sartan products, organic solvents containing amide groups might form secondary amines in acidic solution at high temperature, and then react with nitrous acid, thereby leading to the formation of N-nitrosamines (Scherf-Clavel et al. 2019). Since this reaction probably occurred in syntheses of various sartan substances, many kinds of $\mathrm{N}$-nitrosamines might be found in the sartan products.

N-Nitrosamine GTIs have been recognized as a kind of potent carcinogens. They showed mutagenic activities in Ames test with Salmonella typhimurium and triggered the carcinogenic effect in rats, mice, hamsters, guinea pigs, and rabbits (Wagner et al. 2012; Santos et al. 2014; Buist et al. 2015; Ravnum et al. 2014). Since the valsartan and losartan products produced by several pharmaceutical companies were proven to contain potential contamination with carcinogenic nitrosamine impurities, namely, $\mathrm{N}$-nitrosodimethylamine (NDMA), N-nitrosodiethylamine (NDEA), and $\mathrm{N}$-nitroso-N-methyl-4-aminobutyric acid (NMBA) (Fig. 1), FDA has recalled them since July 2018 (Parr and Joseph 2019).

Recently, GC and LC tandem mass spectrometry have been widely used in the detection of $\mathrm{N}$ nitrosamines in water (Chen et al. 2017; Ngongang et al. 2015), food (Herrmann et al. 2014; Scheeren et al. 2015), and personal care products (Miralles et al. 2019). Pre-treatment methods, for example, solid-phase extraction (Sieira et al. 2020; Luo et al. 2016; McDonald et al. 2012), liquid extraction (Hong et al. 2017), and simultaneous distillation extraction (Zhu et al. 2019) have been commonly used to extract $\mathrm{N}$-nitrosamines from matrix before analysis. However, the determination of $\mathrm{N}$-nitrosamines in APIs through LC-MS/MS and/or GC-MS/MS is not well understood till now. Sörgel group (Sörgel et al. 2019) developed a highly sensitive HPLC-APCI-MS/ MS method for quantitation of NDMA and NDEA in sartan substances. In their work, the limits of quantification (LOQs) and detection (LODs) for NDMA and NDEA were $0.26 \mathrm{ppb}$ and $0.13 \mathrm{ppb}$, respectively, and the recoveries were in the range of 94.2-102.3\%. Schmidtsdorff et al. (Schmidtsdorff and Schmidt 2019) developed a supercritical fluid chromatographyMS/MS method to determine eight $\mathrm{N}$-nitrosamines in sartan drugs, including NDMA, NDEA, and NDBA, in which the running time was less than $20 \mathrm{~min}$ and the LODs for eight $\mathrm{N}$-nitrosamines were in the range of 0.02-0.46 ppm. FDA has established the interim acceptable daily intake limits for $\mathrm{N}$-nitrosamines in sartan substances (Table 1) (US FDA, 2019a, d), and applied GC-MS/MS through utilizing liquid injection and headspace (US FDA, 2019b), RapidFire-MS/MS (US FDA, 2019c), and HPLC-HRMS (US FDA, 2019e)

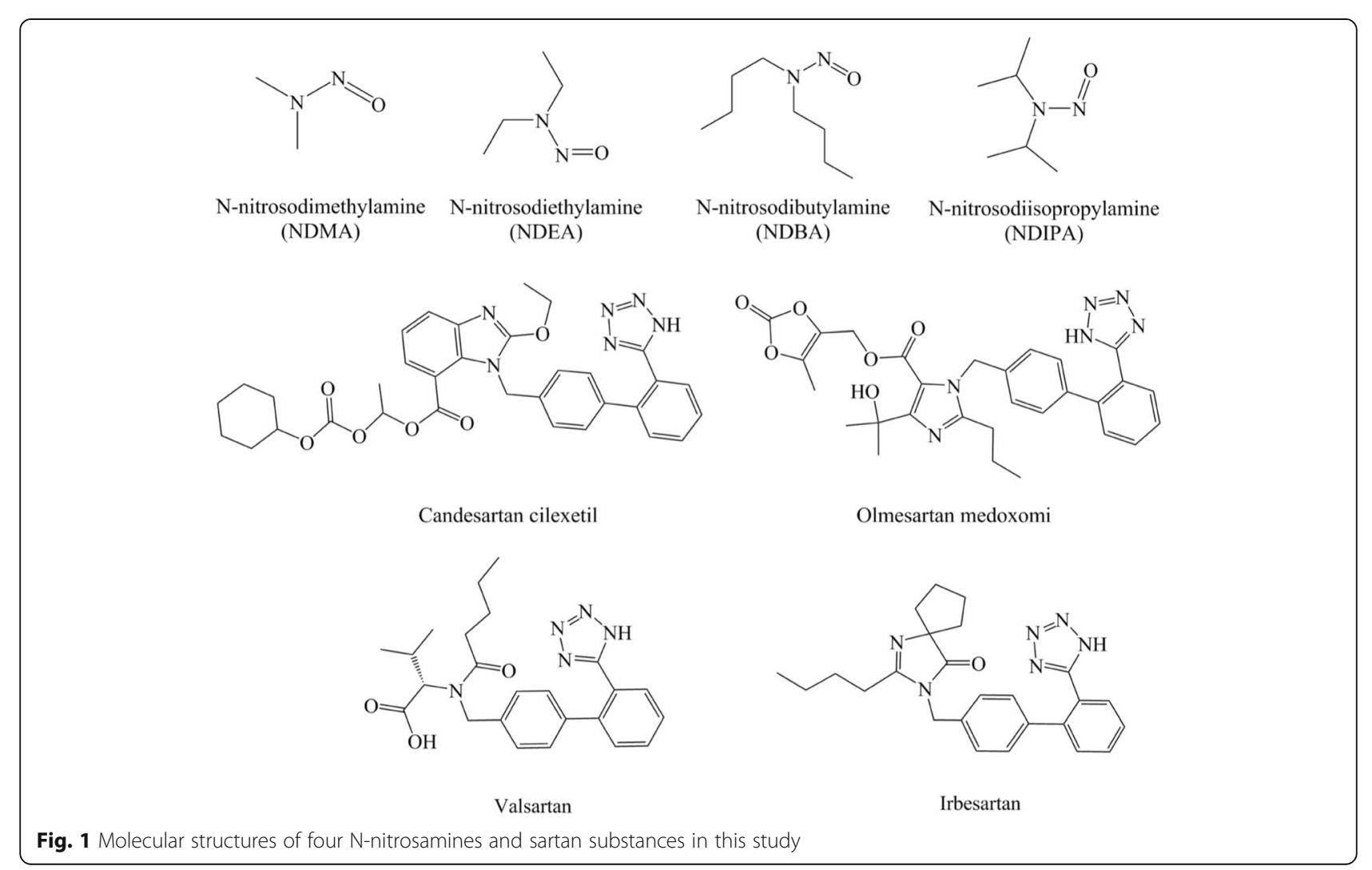


Table 1 Interim limits for NDMA and NDEA in sartan substances set by FDA

\begin{tabular}{llllll}
\hline Sartan & $\begin{array}{l}\text { Maximum daily dose } \\
(\mathbf{m g} / \text { day) }\end{array}$ & $\begin{array}{l}\text { Acceptable intake } \\
\text { NDMA (ng/day) }\end{array}$ & $\begin{array}{l}\text { Acceptable intake } \\
\text { NDMA (ppm) }\end{array}$ & $\begin{array}{l}\text { Acceptable intake } \\
\text { NDEA (ng/day) }\end{array}$ & $\begin{array}{l}\text { Acceptable intake } \\
\text { NDEA (ppm) }\end{array}$ \\
\hline $\begin{array}{l}\text { Candesartan } \\
\text { cilexetil }\end{array}$ & 32 & 96 & 3.0 & 26.5 & 0.83 \\
$\begin{array}{l}\text { Olmesartan } \\
\text { medoxomi }\end{array}$ & 40 & 96 & 2.4 & 26.5 & 0.66 \\
Irbesartan & 300 & & & & \\
Valsartan & 320 & 96 & 0.32 & 26.5 & 0.088 \\
\hline
\end{tabular}

for quantitation of the $\mathrm{N}$-nitrosamines in sartan substances.

It was very necessary for complex matrices of food, water, and personal care products to take extraction and purification steps during the analysis. However, these were not suitable for rapid and high-throughput analysis in the pharmaceutical industry. Herein, we have developed a simple, sensitive, accurate, and reproducible GCMS/MS method by direct injection for the detection of four $\mathrm{N}$-nitrosamines in four sartan substances, namely, candesartan cilexetil, olmesartan medoxomi, irbesartan, and valsartan (Fig. 1). The obtained LODs and LOQs met the sensitivity requirements set by FDA. Then, this developed method was validated according to the International Council for Harmonization (ICH) guidelines in terms of sensitivity, linearity, accuracy, precision, specificity, and stability.

\section{Materials and methods Chemicals and materials}

Four kinds of sartan drugs, namely, candesartan cilexetil, olmesartan medoxomi, irbesartan, and valsartan were friendly provided by a local pharmaceutical company (Zhuhai, China). NDMA (purity $\geq 99.3 \%$ ) and NDBA (purity $\geq 99.9 \%$ ) standards were purchased from Tokyo Chemical Industry (Shanghai) Co. Ltd. (Shanghai, China). NDEA (purity $\geq 99.0 \%$ ) was bought from Adamas Reagent Ltd. (Shanghai, China). NDIPA (purity $\geq$ 99.0\%) was obtained from Beijing Manhage Biotechnology Co. Ltd. (Beijing, China). NDMA-d 6 (purity $\geq 99.5 \%$ ) was bought from Cato Research Chemicals Inc. (Guangzhou, China). HPLC-grade methanol, acetonitrile, ethyl acetate, acetone were purchased from LabScience Inc. (Pittsburg, USA).

\section{Instrumentation and optimized GC-MS/MS conditions}

Analyses of N-nitrosamines were performed on an Agilent 7890B gas chromatography-tandem mass spectrometry with the Agilent 7693A auto sampler system. Agilent VF-Wax ultra-inert capillary column $(30 \mathrm{~m} \times$ $0.25 \mathrm{~mm}$ i.d., $1.0 \mu \mathrm{m}$ ) was used as the analytical column in this work. MS/MS detection was carried out on a Waters Xevo TQ-GC triple quadrupole mass spectrometer with electron ionization (EI) ion source. The GC oven program utilized an initial oven temperature of $40{ }^{\circ} \mathrm{C}$, held for $0.5 \mathrm{~min}$, raised firstly at $20^{\circ} \mathrm{C} \cdot \mathrm{min}^{-1}$ to $200^{\circ} \mathrm{C}$, then to $240{ }^{\circ} \mathrm{C}$ at $40{ }^{\circ} \mathrm{C} / \mathrm{min}$, finally held for $3 \mathrm{~min}$. The total run time was $12.5 \mathrm{~min}$. Helium as the carrier gas was set at a flow of $1.0 \mathrm{~mL} / \mathrm{min}$. Both the interface temperature and injection temperature were set to be $250{ }^{\circ} \mathrm{C}$. The injection volume was $1 \mu \mathrm{L}$ in the splitless mode.

The MS was operated in EI mode at $70 \mathrm{eV}$ with a quadrupole temperature of $150{ }^{\circ} \mathrm{C}$. The temperature of the ion source was set at $200{ }^{\circ} \mathrm{C}$. The delay time of the solvent was $5 \mathrm{~min}$. Multiple reactions monitoring (MRM) mode was selected as the data acquisition for the quantitative determination of four kinds of $\mathrm{N}$ nitrosamine GTIs. The precursor ions and product ions of four N-nitrosamine GTIs, as well as the optimized collision energy (CE) were summarized in Table 2.

\section{Preparation of standard and sample solutions}

The standard stock solutions of NDMA- $\mathrm{d}_{6}$, NDMA, NDEA, NDBA, and NDIPA with each concentration of $1 \mathrm{mg} \cdot \mathrm{mL}^{-1}$ were prepared by dissolving accurately weighed reference standards in methanol, respectively, and stored at $4{ }^{\circ} \mathrm{C}$. For NDMA and NDIPA, a series of standard working solutions at the concentrations of 3,6 , $15,24,30,36,45$, and $60 \mathrm{ng} \cdot \mathrm{mL}^{-1}$ in methanol were obtained from a stock solution through the serial dilution method. The concentrations of series standard working solution for NEDA were $0.8,1.6,4.0,6.4,8.0,9.6,12$, and $16 \mathrm{ng} \cdot \mathrm{mL}^{-1}$, respectively. In addition, the concentrations of the working solution for NDBA were $6,15,24$, $30,36,45$, and $60 \mathrm{ng} \cdot \mathrm{mL}^{-1}$, respectively.

In this work, the concentration of NDMA- $\mathrm{d}_{6}$ (the internal standard) was fixed to be $50 \mathrm{ng} \cdot \mathrm{mL}^{-1}$. Candesartan cilexetil and olmesartan medoxomi were dissolved in methanol at a concentration of $10 \mathrm{mg} \cdot \mathrm{mL}^{-1}$. Valsartan was also dissolved in methanol at a concentration of $100 \mathrm{mg} \cdot \mathrm{mL}^{-1}$. Sample preparation for irbesartan was described as follows. Firstly, $1.0 \mathrm{~g}$ of irbesartan was accurately weighed into a $10-\mathrm{mL}$ volumetric flask and $10 \mathrm{~mL}$ of NDMA- $\mathrm{d}_{6}$ solution was added. Then, after sonicated for $30 \mathrm{~min}$, the mixture was placed in a centrifuge tube and vortexed for $1 \mathrm{~min}$, and then centrifuged at 2500 rpm for $10 \mathrm{~min}$. Finally, the supernatant was filtered with 
Table 2 Multiple reactions monitoring (MRM) transitions and optimized collision energy for four N-nitrosamine GTIs and the internal standard (NDMA-d $)$

\begin{tabular}{|c|c|c|c|}
\hline Analyte & Precursor $\rightarrow$ product $(\mathrm{m} / \mathrm{z})$ & Dwell time (ms) & Collision energy $(\mathrm{eV})$ \\
\hline N-Nitrosodimethylamine- $d_{6}\left(N D M A-d_{6}\right)$ & $80 \rightarrow 50$ & 100 & 5 \\
\hline \multirow[t]{2}{*}{ N-Nitrosodimethylamine (NDMA) } & $74 \rightarrow 44$ & 150 & 5 \\
\hline & $74 \rightarrow 42$ & 50 & 10 \\
\hline \multirow[t]{2}{*}{ N-Nitrosodiethylamine (NDEA) } & $102 \rightarrow 56$ & 150 & 12 \\
\hline & $102 \rightarrow 85$ & 150 & 6 \\
\hline \multirow[t]{2}{*}{ N-Nitrosodiisopropylamine (NDIPA) } & $130 \rightarrow 88$ & 150 & 6 \\
\hline & $130 \rightarrow 42$ & 150 & 10 \\
\hline \multirow[t]{2}{*}{ N-nitrosodibutylamine (NDBA) } & $158 \rightarrow 99$ & 150 & 10 \\
\hline & $84 \rightarrow 56$ & 150 & 12 \\
\hline
\end{tabular}

a $0.22 \mu \mathrm{m}$ nylon syringe filter into a vial for chromatographic injection.

\section{Method validation}

The quantification method of four N-nitrosamines through GC-MS/MS with MRM mode was validated through the following parameters, such as system suitability, specificity, sensitivity, linearity, LOD, LOQ, accuracy, precision, and solution stability. The LODs were defined as 3 times the signal-to-noise $(\mathrm{S} / \mathrm{N})$ ratio, and the corresponding LOQs were $S / N=10$. The matrix effect (ME) value was calculated according to the following equation (Chawla et al. 2017):

$\mathrm{ME} \%=\frac{\text { Slope of matrix matched curve }- \text { slope of solvent curve }}{\text { Slope of solvent curve }} \times 100$

Accuracy of this proposed method was evaluated by the recovery assays at three spiked levels in the blank sartan samples. Moreover, precision was estimated by interday and intraday relative standard deviations (RSDs) of six samples spiked at one concentration over 3 continuous days.

\section{Results and discussion Method development Optimization of the sample solvent}

Methanol, $\mathrm{CH}_{2} \mathrm{Cl}_{2}$, ethyl acetate, and acetone were used for the solubility study of four APIs, and the results were summarized in Supplementary Information Table S1. The solubility of valsartan, irbesartan, and olmesartan medoxomi in methanol was much higher than that in the other three solvents. For valsartan, it was up to 600 $\mathrm{mg} \cdot \mathrm{mL}^{-1}$. Candesartan cilexetil showed the best solubility in $\mathrm{CH}_{2} \mathrm{Cl}_{2}$ among four organic solvents. Taking into consideration of the trace level nature of $\mathrm{N}$-nitrosamine GTIs in the selected APIs, good solubility of the sartan in the selected solvent would helpfully meet the requirements for the safety control of $\mathrm{N}$-nitrosamines.
Therefore, methanol was selected to dissolve the sartan drugs in the following work.

\section{Investigation of mass spectrometric method}

The trace detection method for GTIs is a very crucial part in the analysis of pharmaceuticals. Herein, the LODs and LOQs for N-nitrosamines were used to evaluate the difference of single ion monitoring (SIM) mode and MRM mode in triple quadrupole mass spectrometer. As summarized in Supplementary Information Table S2, the LODs and LOQs for four kinds of Nnitrosamines in SIM mode ranged from 10-50 ng. $\mathrm{mL}^{-1}$ and 25-150 ng. $\mathrm{mL}^{-1}$, respectively. Through using MRM mode, the LODs and LOQs remarkably decreased to 0.2-1.5 ng. $\mathrm{mL}^{-1}$ and $0.8-5.0 \mathrm{ng} \cdot \mathrm{mL}^{-1}$, respectively. Clearly, the MRM mode for the quantification of $\mathrm{N}$ nitrosamines was more highly sensitive than the SIM mode. The latter mode is difficult to meet the sensitivity requirements for the interim limits (Table 1). Therefore, MRM mode was selected as the MS method in the following quantification of four N-nitrosamine GTIs in sartan substances.

\section{Matrix effect}

In the GC system, the matrix effect (ME) might be caused through masking silanol active sites in the injection liner and GC column (Rimayi et al. 2015). Herein, the ME was investigated through comparing the slope between the standard solvent curve and the matrix-matched standard curve. Matrix effect can be negligible in the quantification when the value is less than 15\% (Chawla et al. 2017). In Table 3, the signal enhancements for NDEA in candesartan cilexetil and valsartan, NDIPA in olmesartan medoxomi, and NDBA in valsartan were observed, and the ME values were in the range of 20.47-56.41\%, indicating that the matrix effect could not be negligible. In addition, no significant suppression or enhancement differences for the others were observed. Therefore, in order to 
Table 3 Comparison of the calibration curves and calculation of matrix effect (ME) for N-nitrosamines in solvent and in sartan matrices

\begin{tabular}{|c|c|c|c|c|c|}
\hline Analyte & Calibration (matrix) & Linearity range $\left(\mathrm{ng} \cdot \mathrm{mL}^{-1}\right)$ & Regression equation & $R^{2}$ & ME \\
\hline \multirow[t]{5}{*}{$\overline{N D M A}$} & Methanol & $3 \sim 60$ & $y=0.0122 x-0.0054$ & 0.9989 & \\
\hline & Candesartan cilexetil & & $y=0.0121 x-0.0037$ & 0.9994 & $-0.82 \%$ \\
\hline & Olmesartan medoxomi & & $y=0.0121 x-0.0047$ & 0.9988 & $-0.82 \%$ \\
\hline & Irbesartan & & $y=0.0120 x-0.0012$ & 0.9958 & $-1.64 \%$ \\
\hline & Valsartan & & $y=0.0118 x+0.0162$ & 0.9981 & $-3.28 \%$ \\
\hline \multirow[t]{5}{*}{ NDEA } & Methanol & $0.8 \sim 16$ & $y=0.0127 x-0.0025$ & 0.9976 & \\
\hline & Candesartan cilexetil & & $y=0.0189 x-0.0015$ & 0.9981 & $48.82 \%$ \\
\hline & Olmesartan medoxomi & & $y=0.0130 x+0.0009$ & 0.9989 & $2.36 \%$ \\
\hline & Irbesartan & & $y=0.0126 x+0.1833$ & 0.9934 & $-0.79 \%$ \\
\hline & Valsartan & & $y=0.0153 x-0.0159$ & 0.9952 & $20.47 \%$ \\
\hline \multirow[t]{5}{*}{ NDIPA } & methanol & $3 \sim 60$ & $y=0.0109 x-0.0094$ & 0.9987 & \\
\hline & Candesartan cilexetil & & $y=0.0115 x-0.0052$ & 0.9993 & $5.50 \%$ \\
\hline & Olmesartan medoxomi & & $y=0.0140 x-0.0120$ & 0.9966 & $28.44 \%$ \\
\hline & Irbesartan & & $y=0.0109 x-0.0124$ & 0.9948 & $0.00 \%$ \\
\hline & Valsartan & & $y=0.0114 x-0.0079$ & 0.9985 & $4.59 \%$ \\
\hline \multirow[t]{5}{*}{ NDBA } & Methanol & $6 \sim 60$ & $y=0.0039 x-0.0014$ & 0.9976 & \\
\hline & Candesartan cilexetil & & $y=0.0042 x-0.0006$ & 0.9994 & $7.69 \%$ \\
\hline & Olmesartan medoxomi & & $y=0.0042 x-0.0019$ & 0.9989 & $7.69 \%$ \\
\hline & Irbesartan & & $y=0.0034 x+0.0634$ & 0.9656 & $-12.82 \%$ \\
\hline & Valsartan & & $y=0.0061 x+0.0200$ & 0.9940 & $56.41 \%$ \\
\hline
\end{tabular}

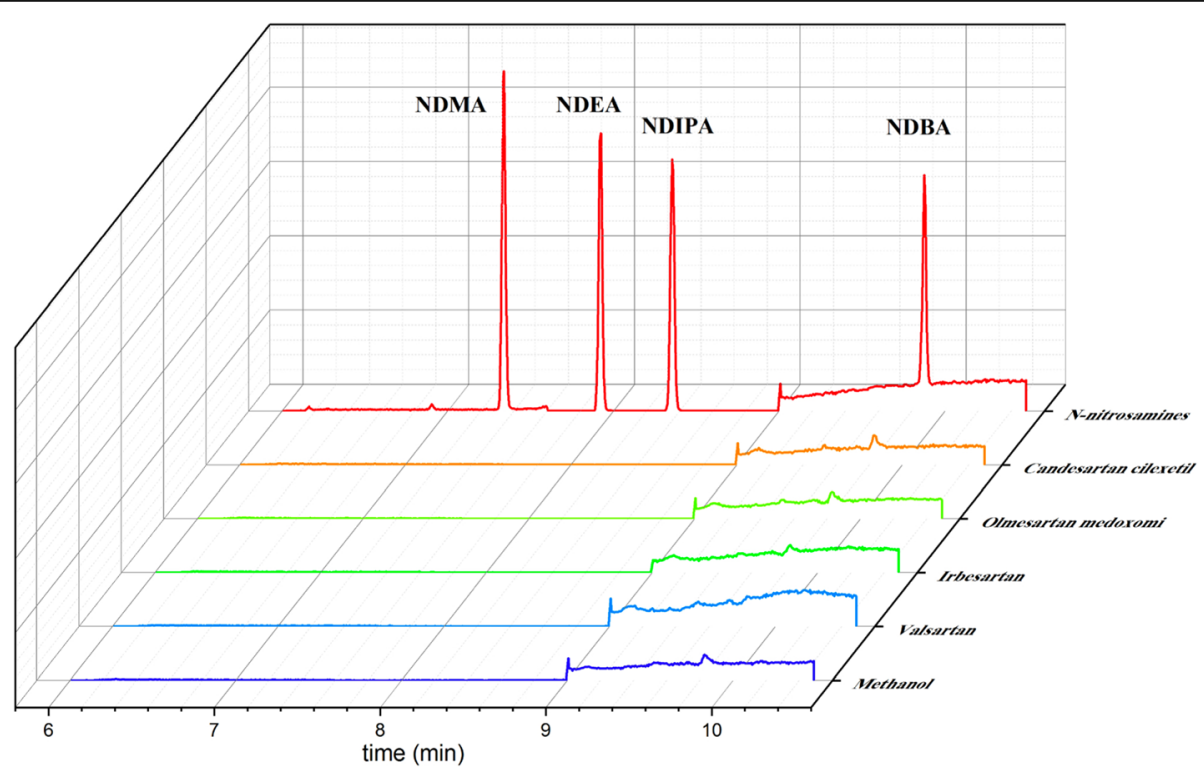

Fig. 2 GC chromatograms of methanol, four sartan substances, and the mixed standard solution of four $\mathrm{N}$-nitrosamines 
obtain accurate result, calibration of $\mathrm{N}$-nitrosamines in sartan substances has been performed through internal matrix-matched standards in the recovery assay.

\section{Method validation}

The proposed determination method for four Nnitrosamine GTIs has been validated according to the $(\mathrm{ICH})$ guidelines.

\section{Specificity}

To demonstrate the specificity of the proposed method, methanol, the sartan matrices, and the mixture solution of four $\mathrm{N}$-nitrosamine standards were subjected to the GC-MS/MS analysis. In Fig. 2, no interference peaks in the solvent and the sartan matrices were observed at the retention times of four $\mathrm{N}$-nitrosamines, indicating that this method for the determination of four $\mathrm{N}$ nitrosamines in sartan substances showed good specificity.

\section{Linearity and sensitivity}

Linearity, LODs, and LOQs results were summarized in Table 4. The chromatographic peak area ratio (N-nitrosamines/NDMA- $\left.\mathrm{d}_{6}, y\right)$ were plotted against standard concentrations of $\mathrm{N}$-nitrosamines $(x)$, and the standard curves were in the form of $y=A x+B$, in which $A$ and $B$ represented as the slope and the intercept, respectively. Eight standard concentrations were evaluated to verify the linearity of the analysis method. The linearity for four N-nitrosamines was established in the tested concentration range. The linear regression coefficients of determination $\left(R^{2}\right)$ for four $\mathrm{N}$-nitrosamines were over 0.99 in the corresponding concentration range, which meant a good linearity and suitable for quantitative analysis.

Then, the sensitivity of the method was assessed according to the LODs and LOQs, respectively. In Table 5, the LODs for NDMA, NDEA, NDIPA, and NDBA in methanol were determined to be $1.2,0.2,0.4$, and 1.5 $\mathrm{ng} \cdot \mathrm{mL}^{-1}$, respectively, which relative to four sartan substances were in the range of $0.002-0.150 \mathrm{ppm}$. The LOQs for NDMA, NDEA, NDIPA, and NDBA in methanol were $3.0,0.8,1.0$, and $5.0 \mathrm{ng} \cdot \mathrm{mL}^{-1}$, respectively, which relative to four sartan substances were in the range of $0.008-0.500 \mathrm{ppm}$. These low LODs and LOQs values for this GC-MS/MS method were satisfactory and adequate for the detection of $\mathrm{N}$-nitrosamines in sartan samples.

\section{Accuracy}

Method accuracy was determined by using six replicate samples for each sartan substance. The recoveries of four $\mathrm{N}$-nitrosamines were measured to assess the performance of the proposed GC-MS/MS method by spiking the blank samples with three different concentrations of which were $50 \%, 100 \%$, and $150 \%$ of the limits, respectively. According to the daily exposure and the $\mathrm{TD}_{50}$ value, the limits of NDMA and NDEA in sartan set by FDA were validated in accuracy assays. Considering the toxicity of NDIPA and NDBA has been less than NDMA and the risk for occurrence would be lower than NDMA, the concentration limits for NDIPA and NDBA validated in accuracy assays were set to be the same with NDMA in this study. The results exhibited that the recoveries for NDMA, NDEA, NDIPA, and NDBA in four sartan substances ranged from 87.68 to $123.76 \%$ (Supplementary Information Table S3). Since the acceptance criteria for recovery was refined to be in the range of $70-130 \%$ according to the ultra-trace level nature of the analysis, the recoveries for four $\mathrm{N}$ nitrosamines in this work can meet that criteria.

\section{Precision}

Method precision was evaluated by both intraday and interday precisions. The intraday precision was measured by comparing the standard deviation of the recovery percentages of the spiked samples ran during the same day. The interday precision was determined by analyzing the spiked samples for three distinct days. As summarized in Table 5, this GC-MS/MS method exhibited satisfactory mean recovery values (75.07-116.44\%) and precision, in which the RSD values for the intraday and interday precision were in the range of $1.45-6.38 \%$ and $2.88-9.15 \%$, respectively.

\section{Stabilities of four $\mathrm{N}$-nitrosamines in methanol}

Solution stabilities of four N-nitrosamines in methanol solutions were evaluated by preparing $30 \mathrm{ng} \cdot \mathrm{mL}^{-1}$

Table 4 Calibration curves, LODs, and LOQs for four N-nitrosamines

\begin{tabular}{|c|c|c|c|c|c|c|c|c|c|c|c|c|c|}
\hline \multirow[t]{2}{*}{ Analyte } & \multirow{2}{*}{$\begin{array}{l}\text { Linearity } \\
\text { range } \\
\left(\mathrm{ng} \cdot \mathrm{mL}^{-1}\right)\end{array}$} & \multirow{2}{*}{$\begin{array}{l}\text { Regression } \\
\text { equation }\end{array}$} & \multirow[t]{2}{*}{$R^{2}$} & \multicolumn{2}{|c|}{ Methanol } & \multicolumn{2}{|c|}{ Candesartan cilexetil } & \multicolumn{2}{|c|}{ Olmesartan medoxomi } & \multicolumn{2}{|c|}{ Irbesartan } & \multicolumn{2}{|c|}{ Valsartan } \\
\hline & & & & $\begin{array}{l}\text { LOD } \\
\text { (ng.m }\end{array}$ & $\begin{array}{l}\text { LOQ } \\
\left.\mathrm{hL}^{-1}\right)\end{array}$ & $\begin{array}{l}\text { LOD } \\
\text { (ppm) }\end{array}$ & LOQ & LOD & LOQ & $\overline{L O D}$ & $\overline{L O Q}$ & LOD & LOQ \\
\hline$\overline{N D M A}$ & $3.0-60$ & $y=0.0114 x-0.0034$ & 0.9968 & 1.2 & 3.0 & 0.120 & 0.300 & 0.120 & 0.300 & 0.012 & 0.030 & 0.012 & 0.030 \\
\hline NDEA & $0.8-16$ & $y=0.0130 x-0.0032$ & 0.9926 & 0.2 & 0.8 & 0.020 & 0.080 & 0.020 & 0.080 & 0.002 & 0.008 & 0.002 & 0.008 \\
\hline NDIPA & $3.0-60$ & $y=0.0112 x-0.0004$ & 0.9977 & 0.4 & 1.0 & 0.040 & 0.100 & 0.040 & 0.100 & 0.004 & 0.010 & 0.004 & 0.010 \\
\hline NDBA & $6.0-60$ & $y=0.0038 x+0.0022$ & 0.9947 & 1.5 & 5.0 & 0.150 & 0.500 & 0.150 & 0.500 & 0.015 & 0.050 & 0.015 & 0.050 \\
\hline
\end{tabular}


Table 5 Precision assay results of four $\mathrm{N}$-nitrosamines in sartan substances.

\begin{tabular}{|c|c|c|c|c|c|c|c|c|c|c|}
\hline \multirow[t]{3}{*}{ Matrix } & \multirow[t]{3}{*}{ Compound } & \multirow{3}{*}{$\begin{array}{l}\text { Spiked } \\
\text { level } \\
(\mathrm{ppm})\end{array}$} & \multicolumn{6}{|c|}{ Intraday $(n=6)$} & \multicolumn{2}{|c|}{$\begin{array}{l}\text { Interday }(n= \\
18)\end{array}$} \\
\hline & & & \multicolumn{2}{|l|}{ Day 1} & \multicolumn{2}{|l|}{ Day 2} & \multicolumn{2}{|l|}{ Day 3} & \multirow{2}{*}{$\begin{array}{l}\text { Average } \\
\text { recovery } \\
(\%)\end{array}$} & \multirow{2}{*}{$\begin{array}{l}\text { RSD } \\
(\%)\end{array}$} \\
\hline & & & $\begin{array}{l}\text { Average } \\
\text { recovery (\%) }\end{array}$ & $\begin{array}{l}\text { RSD } \\
(\%)\end{array}$ & $\begin{array}{l}\text { Average } \\
\text { recovery (\%) }\end{array}$ & $\begin{array}{l}\text { RSD } \\
(\%)\end{array}$ & $\begin{array}{l}\text { Average } \\
\text { recovery (\%) }\end{array}$ & $\begin{array}{l}\text { RSD } \\
(\%)\end{array}$ & & \\
\hline \multirow{4}{*}{$\begin{array}{l}\text { Candesartan } \\
\text { cilexetil }\end{array}$} & NDMA & 3.0 & 101.06 & 3.75 & 102.37 & 2.57 & 99.40 & 3.98 & 100.94 & 3.49 \\
\hline & NDEA & 0.80 & 109.56 & 4.15 & 107.83 & 3.62 & 106.31 & 5.98 & 107.90 & 4.57 \\
\hline & NDIPA & 3.0 & 97.49 & 5.50 & 95.90 & 6.38 & 93.88 & 4.74 & 95.76 & 5.49 \\
\hline & NDBA & 3.0 & 91.69 & 2.08 & 97.64 & 3.80 & 92.11 & 5.09 & 93.82 & 4.69 \\
\hline \multirow{4}{*}{$\begin{array}{l}\text { Olmesartan } \\
\text { medoxomi }\end{array}$} & NDMA & 2.4 & 79.76 & 4.69 & 89.26 & 4.84 & 96.31 & 4.91 & 88.45 & 9.15 \\
\hline & NDEA & 0.64 & 75.07 & 1.45 & 84.66 & 3.57 & 81.84 & 6.21 & 80.52 & 6.55 \\
\hline & NDIPA & 2.4 & 91.83 & 4.32 & 83.23 & 3.57 & 82.68 & 4.28 & 86.39 & 6.05 \\
\hline & NDBA & 2.4 & 83.41 & 6.05 & 85.34 & 4.14 & 94.63 & 5.00 & 87.79 & 7.04 \\
\hline \multirow[t]{4}{*}{ Irbesartan } & NDMA & 0.3 & 106.18 & 3.17 & 104.67 & 2.15 & 104.60 & 3.43 & 105.15 & 2.88 \\
\hline & NDEA & 0.08 & 95.66 & 3.64 & 98.21 & 3.65 & 91.78 & 3.16 & 95.22 & 4.36 \\
\hline & NDIPA & 0.3 & 92.46 & 3.36 & 91.35 & 4.27 & 92.62 & 4.63 & 92.14 & 3.92 \\
\hline & NDBA & 0.3 & 114.14 & 3.85 & 109.58 & 3.45 & 116.44 & 3.99 & 113.39 & 4.40 \\
\hline \multirow[t]{4}{*}{ Valsartan } & NDMA & 0.3 & 101.45 & 3.34 & 101.88 & 3.64 & 102.95 & 3.26 & 102.09 & 3.27 \\
\hline & NDEA & 0.08 & 108.92 & 5.35 & 106.37 & 5.70 & 102.92 & 4.83 & 106.07 & 5.54 \\
\hline & NDIPA & 0.3 & 92.43 & 3.33 & 94.97 & 5.09 & 96.30 & 4.83 & 96.78 & 6.37 \\
\hline & NDBA & 0.3 & 108.74 & 4.06 & 113.88 & 4.65 & 106.21 & 3.17 & 109.61 & 4.84 \\
\hline
\end{tabular}

standard solutions and analyzing them every 4 or $12 \mathrm{~h}$ against a freshly prepared standard. All the solutions were kept in the dark place at $25^{\circ} \mathrm{C}$. The results are summarized in Supplementary Information Table S4. Clearly, the percentage recoveries of these stock solutions were in the range of $97.51-105.04 \%$, and the difference between recoveries at $0 \mathrm{~h}$ and $24 \mathrm{~h}$ were not more than $10 \%$, which indicated that these stock solutions were stable for at least $24 \mathrm{~h}$.

\section{Applications in sartan samples}

This GC-MS/MS analytical method was used to determine four N-nitrosamine GTIs in Chinese commercial sartan products, and no N-nitrosamines were found in four batches of sartan substances (Supplementary Information Table S5).

\section{Conclusions}

As a result, a sensitive and simple GC-MS/MS method with MRM mode was developed for the determination of NDMA, NDEA, NDIPA, and NDBA in sartan substances. This GC-MS/MS method presented satisfactory selectivity and sensitivity. The analysis time was less than 13 min. More importantly, the LODs and LOQs of four $\mathrm{N}$-nitrosamines were in the range of $0.002-0.150 \mathrm{ppm}$ and $0.008-0.500 \mathrm{ppm}$, respectively, which was proved to be suitable for sensitive quantification of four $\mathrm{N}$ nitrosamines in sartan products.

\section{Supplementary Information}

The online version contains supplementary material available at https://doi. org/10.1186/s40543-020-00254-2.

Additional file 1: Table S1. Solubility results of sartan substances in four organic solvents. Table S2. LODs and LOQs for four N-nitrosamines through using different MS method. Table S3. Recovery assay results of $\mathrm{N}$-nitrosamines in four sartan matrices through the proposed GC-MS/MS method. Table S4. Recovery results for stability assays of N-nitrosamines in methanol. Table S5. Results of N-nitrosamines in four batches of commercial sartan substances.

\section{Abbreviations}

APCI: Atmospheric pressure chemical ionization; APIs: Active pharmaceutical ingredients; FDA: Food and Drug Administration; GTI: Genotoxic impurity; ICH: International Council for Harmonization; LOD: Limit of detection; LOQ: Limit of quantification; ME: Matrix effect; MRM: Multiple reactions monitoring; NDBA: N-nitrosodibutylamine; NDEA: N-nitrosodiethylamine; NDIPA: N-nitrosodiisopropyl amine; NDMA: N-nitrosodimethylamine; RSD: Relative standard deviation; SIM: Single ion monitoring; S/N: Signal to noise

\section{Acknowledgements}

Not applicable in this section.

\section{Authors' contributions}

ZWG designed this study and gave constructive advices of the project and the manuscript. XB performed the material preparation. The GC-MS/MS analysis work was performed by MBL, HRJ, and ZZF. GD did pre-treatment of sartan samples. CQ performed the data analysis of the obtained results. $L J$ finished the draft of the manuscript. FJ revised the manuscript. All authors read and approved the final manuscript. 


\section{Funding}

This work was supported by the National Natural Science Foundation of China under Grant number 21571070 and Natural Science Foundation of Guangdong Province under Grant number 2018A030313193.

\section{Availability of data and materials}

All data generated or analyzed during this study are included in this published article and its supplementary information files.

\section{Competing interests}

The authors declare that they have no conflict of interest.

\section{Author details}

${ }^{1}$ Zhuhai Rundu Pharmaceutical Co. Ltd., Zhuhai 519040, China. ${ }^{2}$ School of Chemistry, South China Normal University, Guangzhou 510006, China. ${ }^{3}$ Guangzhou Research \& Creativity Biotechnology Co. Ltd., Guangzhou 510663, China.

Received: 26 July 2020 Accepted: 9 December 2020

Published online: 08 January 2021

\section{References}

Benigni R, Bossa C. Mechanisms of chemical carcinogenicity and mutagenicity: a review with implications for predictive toxicology. Chem Rev. 2011;111:250736.

Buist HE, Devito S, Goldbohm RA, Stierum RH, Venhorst J, Kroese ED. Hazard assessment of nitrosamine and nitramine by-products of amine-based CCS: alternative approaches. Regul Toxicol Pharm. 2015;71:601-23.

Chawla S, Patel HK, Gor HN, Vaghela KM, Solanki PP, Shah PG. Evaluation of matrix effects in multiresidue analysis of pesticide residues in vegetables and spices by LC-MS/MS. J. AOAC Int. 2017;100:616-23.

Chen WW, Li XS, Huang HF, Zhu XT, Jiang XY, Zhang Y, Cen K, Zhao LS, Liu XL, Qi SH. Comparison of gas chromatography-mass spectrometry and gas chromatography-tandem mass spectrometry with electron ionization for determination of $\mathrm{N}$-nitrosamines in environmental water. Chemosphere. 2017;168:1400-10.

Herrmann SS, Duedahl-Olesen L, Granby K. Simultaneous determination of volatile and non-volatile nitrosamines in processed meat products by liquid chromatography tandem mass spectrometry using atmospheric pressure chemical ionisation and electrospray ionisation. J Chromatogr A. 2014;1330: 20-9.

Hong Y, Kim KH, Sang BI, Kim H. Simple quantification method for Nnitrosamines in atmospheric particulates based on facile pretreatment and GC-MS/MS. Environ Pollut. 2017;226:324-34

Luo YB, Chen XJ, Zhang HF, Jiang XY, Li X, Li XY, Zhu FP, Pang YQ, Hou HW. Simultaneous determination of polycyclic aromatic hydrocarbons and tobacco-specific $\mathrm{N}$-nitrosamines in mainstream cigarette smoke using inpipette-tip solid-phase extraction and on-line gel permeation chromatography-gas chromatography-tandem mass spectrometry. J Chromatogr A. 2016;1460:16-23.

McDonald JA, Harden NB, Nghiem LD, Khan SJ. Analysis of N-nitrosamines in water by isotope dilution gas chromatography-electron ionisation tandem mass spectrometry. Talanta. 2012;99:146-54.

Miralles P, van Gemert I, Chisvert A, Salvador A. Stir bar sorptive-dispersive microextraction mediated by magnetic nanoparticles-metal organic framework composite: determination of $\mathrm{N}$-nitrosamines in cosmetic products. J Chromatogr A. 2019:1604:460465.

Muszalska I, Sobczak A, Dołhan A, Jelinska A. Analysis of sartans: a review. J Pharmaceut Sci. 2014;103:2-28.

Ngongang AD, Duy SV, Sauvé S. Analysis of nine N-nitrosamines using liquid chromatography-accurate mass high resolution-mass spectrometry on a QExactive instrument. Anal Methods. 2015;7:5748-59.

Parr MK, Joseph JF. NDMA impurity in valsartan and other pharmaceutical products: analytical methods for the determination of $\mathrm{N}$-nitrosamines. Pharmaceut Biomed Anal. 2019;164:536-49.

Raman RWSS, Prasad AVSS, Reddy KR. Strategies for the identification, control and determination of genotoxic impurities in drug substances: a pharmaceutical industry perspective. J Pharmaceut Biomed Anal. 2011;55: $662-7$.
Ravnum S, Rundén-Pran E, Fjellsbø LM, Dusinska M. Human health risk assessment of nitrosamines and nitramines for potential application in $\mathrm{CO}_{2}$ capture. Regul Toxicol Pharm. 2014;69:250-5.

Rimayi C, Odusanya D, Mtunzi F, Tsoka S. Alternative calibration techniques for counteracting the matrix effects in GC-MS-SPE pesticide residue analysis-a statistical approach. Chemosphere. 2015;118:35-43.

Santos NP, Colaco A, da Costa RMG, Oliveira MM, Peixoto F, Oliveira PA. NDiethylnitrosamine mouse hepatotoxicity: time-related effects on histology and oxidative stress. Exp Toxicol Pathol. 2014:66:429-36.

Scheeren MB, Sabik H, Gariépy C, Terra NN, Arul J. Determination of Nnitrosamines in processed meats by liquid extraction combined with gas chromatography-methanol chemical ionisation/mass spectrometry. Food Addit Contam A. 2015;32:1436-47.

Scherf-Clavel O, Kinzig M, Besa A, Schreiber A, Bidmon C, Abdel-Tawab M, Wohlfart J, Sörgel F, Holzgrabe U. The contamination of valsartan and other sartans, Part 2: Untargeted screening reveals contamination with amides additionally to known nitrosamine impurities. J Pharmaceut Biomed Anal. 2019;172:278-84

Schmidtsdorff S, Schmidt AH. Simultaneous detection of nitrosamines and other sartan-related impurities in active pharmaceutical ingredients by supercritical fluid chromatography. J Pharmaceut Biomed Anal. 2019;174:151-60.

Sieira BJ, Carpinteiro I, Rodil R, Quintana JB, Cela R. Determination of Nnitrosamines by gas chromatography coupled to quadrupole-time-of-flight mass spectrometry in water samples. Separations. 2020;7:3.

Sörgel F, Kinzig M, Abdel-Tawab M, Bidmon C, Schreiber A, Ermel S, Wohlfart J, Besa A, Scherf-Clavel O, Holzgrabe U. The contamination of Valsartan and other sartans, part 1: new findings. J Pharmaceut Biomed Anal. 2019;172:395405.

Szekely G, de Sousa MCA, Gil M, Ferreira FC, Heggie W. Genotoxic impurities in pharmaceutical manufacturing: sources, regulations, and mitigation. Chem Rev. 2015:115:8182-229.

Teasdale A, Elder DP. Analytical control strategies for mutagenic impurities: current challenges and future opportunities? Trends Anal Chem. 2014;103:228.

U.S. Food \& Drug Administration (FDA). Combined Direct Injection NNitrosodimethylamine (NDMA), N-Nitrosodiethylamine (NDEA), NNitrosoethylisopropylamine (NEIPA), N-Nitrosodiisopropylamine (NDIPA), and N-Nitrosodibutylamine (NDBA) Impurity Assay by GC-MS/MS. 2019a. https:// www.fda.gov/media/123409/download. Accessed 19 Apr 2019

U.S. Food \& Drug Administration (FDA). Combined Headspace NNitrosodimethylamine (NDMA), N-Nitrosodiethylamine (NDEA), NNitrosoethylisopropylamine (NEIPA), and N-Nitrosodiisopropylamine (NDIPA) Impurity Assay by GC-MS/MS. 2019b. https://www.fda.gov/media/124025/ download. Accessed 29 Apr 2019.

U.S. Food \& Drug Administration (FDA). Development and validation of a RapidFire-MS/MS method for screening of nitrosamine carcinogen impurities N-Nitrosodimethylamine (NDMA), N-Nitrosodiethylamine (NDEA), NNitrosoethylisopropylamine (NEIPA), N-Nitrosodiisopropylamine (NDIPA), NNitrosodibutylamine (NDBA) and N-Nitroso-N-methyl-4-aminobutyric acid (NMBA) in ARB drugs. 2019c. https://www.fda.gov/media/125477/ download. Accessed 24 July 2019.

U.S. Food \& Drug Administration (FDA). FDA updates table of interim limits for nitrosamine impurities in ARBs. 2019d. https://www.fda.gov/drugs/drugsafety-and-availability/fda-updates-and-press-announcements-angiotensin-iireceptor-blocker-arb-recalls-valsartan-losartan\#interimlimits2. Accessed 28 Feb 2019.

U.S. Food \& Drug Administration (FDA). Liquid Chromatography-High Resolution Mass Spectrometry (LC-HRMS) Method for the determination of six nitrosamine impurities in ARB drugs. 2019e. https://www.fda.gov/media/1254 78/download. Accessed 21 May 2019.

Wagner ED, Hsu KM, Lagunas A, Mitch WA, Plewa MJ. Comparative genotoxicity of nitrosamine drinking water disinfection byproducts in Salmonella and mammalian cells. Mutat Rese-Gen Tox Environ. 2012;741:109-15.

Zhu M, Ye Q, Zhou T, Chen L, Yu L, Li B, Hu J, Zhou M. Determination of 10 volatile $\mathrm{N}$-nitrosamines in meat products by gas chromatography-tandem mass spectrometry. Chin. J. Chromatogr. 2019;37:207-15.

\section{Publisher's Note}

Springer Nature remains neutral with regard to jurisdictional claims in published maps and institutional affiliations. 